DOSSIÊ TEMÁTICO: Ensinar e aprender: metodologias e estratégias

d. https://doi.org/10.22481/praxisedu.v15i35.5658

\title{
COTIDIANO E MEMÓRIA DIDÁTICA COMO ESTRATÉGIA NO ENSINO DE FÍSICA
}

\author{
DAILY LIFE AND DIDACTIC MEMORY AS A STRATEGY IN PHYSICAL \\ EDUCATION
}

\section{COTIDIANO Y MEMORIA DIDÁCTICA COMO ESTRATEGIA EN LA ENSEÑANZA DE FÍSICA}

\author{
Álex de Carvalho Ferreira \\ Universidade Estadual do Sudoeste da Bahia - Brasil \\ Ester Maria de Figueiredo Souza \\ Universidade Estadual do Sudoeste da Bahia - Brasil
}

\begin{abstract}
Resumo: O artigo objetiva refletir sobre o ensino da disciplina Física, a partir da mobilização memória didática e do cotidiano. Para tanto, extraem-se essas noções de anotações de aulas observadas, nas turmas do ensino médio de uma professora de uma escola pública. Busca-se explorar os estudos de cotidiano de Certeau (2008; 2009), Ferraço (2013; 2017) e Pais (2001) na intercalação com a concepção de memória didática no cotidiano de situações de ensino e sua contribuição para favorecer aprendizagem significativas dos conceitos e conteúdos da disciplina Física. Sinalizamos a memória como recorte didático para o estudante lembrar e/ou rememorar aspectos realçados na aula a partir de enunciados do professor. Expõem-se como resultados a importância de se considerar aspectos do cotidiano para a produção de metodologias e estratégias diferenciadas que privilegiam a exploração das experiências dos estudantes para se alcançar resultados produtivos do ensino de Física.
\end{abstract}

Palavras-chaves: Cotidiano. Estratégias de Ensino. Memória Didática

\begin{abstract}
The article aims to reflect on the teaching of the subject Physics from the mobilization of didactic memory and daily life. To do so, we extract these notions from notes of observed classes, in the high school classes of a public school teacher. It is sought to explore the studies on daily life of Certeau $(2008$; 2009), Ferraço $(2013,2017)$ and Pais (2001) in the intercalation with the conception of didactic memory in the daily life of teaching situations and their contribution to favor meaningful learning of the concepts and contents of the Physics subject. We signal the memory as a didactic cut for the student to remember and / or to recall aspects emphasized in the class, from the statements of the teacher. The results show the importance of considering daily aspects for the production of differentiated methodologies and strategies that privilege the exploration of students' experiences in order to achieve productive results in Physics teaching.
\end{abstract}

Keywords: Daily life. Teaching strategies. Didactic memory. 
Resumen: El artículo objetiva reflexionar sobre la enseñanza de la asignatura Física, a partir de la movilización memoria didáctica y de lo cotidiano. Para ello, se extraen esas nociones de anotaciones desde la observación de clases de educación secundaria de una profesora de una escuela pública. Se busca explorar los estudios de cotidiano de Certeau (2008; 2009), Ferraço (2013; 2017) y Pais (2001) en la intercalación con la concepción de memoria didáctica en el cotidiano de situaciones de enseñanza y su contribución para favorecer el aprendizaje significativo de los conceptos y contenidos de la asignatura Física. Señalamos la memoria como recorte didáctico para el estudiante recordar y/o rememorar aspectos realzados en la clase, a partir de enunciados del profesor. Se exponen como resultados la importancia de considerar aspectos de lo cotidiano para la producción de metodologías y estrategias diferenciadas que privilegian la explotación de las experiencias de los estudiantes para alcanzar resultados productivos de la enseñanza de Física.

Palabras clave: Cotidiano. Estrategias de Enseñanza. Memoria Didáctica..

\section{Introdução}

As reflexões geradas e expostas neste artigo são decorrentes de pesquisa que abarcam a mobilização da memória didática, enquanto estratégia de aprendizagem, e do cotidiano nas situações de ensino da disciplina Física. A memória é tomada neste artigo desprovida de abordagem cognitivista, visto que nos apoiamos na compreensão de gestos didáticos relativos ao agir do professor para a mobilização da exposição do conteúdo da aula, tomando como foco o gesto didático fundador relativo à mobilização da memória didática (ou memória das aprendizagens).

Assim, situamos que o agir profissional do docente pode ser considerado, no campo dos estudos do ensino como trabalho, um instrumento mediador da atividade de ensinoaprendizagem e, assim, os enunciados docentes que retomam e/ou recuperam as memórias dos conteúdos já expostos é entendido como um instrumental didático.

Estamos, portanto, dialogando com a noção de gestos profissionais, ou gestos didáticos, no caso específico do trabalho do professor (cf. AEBY-DAGHÉ; DOLZ, 2008; NASCIMENTO, 2011), o que explicitaremos no decorrer deste artigo. Também, nos aportamos em Nascimento (2011) quando envolve os gestos didáticos na perspectiva discursiva e de movimentos pragmáticos (NASCIMENTO, 2011) - ou seja, verbais e não verbais. Esses movimentos são materiais e podem ser observados no cotidiano das aulas, no trabalho docente, revelando as circunstâncias e significados das aprendizagens (ou não) dos estudantes.

Uma das questões centrais do ensino de Física na atualidade é a utilização de novos mecanismos na prática docente, metodologias diferenciadas, práticas que permitam aos estudantes a pensar o ensino fora da rotina escolar. Considera-se, portanto, necessário pensar o ensino em discussão, a partir de estratégias capazes de facilitar e proporcionar uma 
aprendizagem significativa aos estudantes, mostrando a utilidade da Ciência Física no cotidiano presente relacionado a memória como cotidiano vivido.

No bojo dessa questão, compreende-se que a Física é uma das Ciências mais utilizadas nas práticas cotidianas de qualquer ser humano, estando fortemente ligada aos nossos fazeres cotidianos e também responsável por diferentes fenômenos naturais ${ }^{1}$ a nossa volta, por isso, entendemos que ensinar física requer mais do que apenas um professor, lousa, pincel e o livro didático, é necessário abordar a Ciência em volta do aluno, utilizando estratégias capazes de promover aprendizagens neste âmbito.

Nesta perspectiva, o presente texto apresenta reflexões embasadas nas noções de cotidiano e memória didática como estratégias mobilizadoras da aprendizagem, enfatizando o professor como instrumento fundamental para essa realização e objetiva refletir sobre o ensino da disciplina Física no ensino médio, a partir da mobilização da ativação memória didática e do cotidiano extraídos dos enunciados docentes na aula de Física.

Trata-se de um artigo da pesquisa em andamento do mestrado, nomeada "Memória e Cotidiano no Ensino de Física a partir dos Letramentos Críticos: potencialidades e articulações”, do Programa de Pós-graduação em Educação-PPGEd, da Universidade Estadual do Sudoeste da Bahia-UESB.

\section{Considerações sobre a noção de cotidiano}

O tema do cotidiano tem sido usado com frequência em estudos da área das Ciências Humanas e da Educação, apontando um interesse dos pesquisadores pelas reconhecidas "questões do dia-a-dia, pelas questões mais rotineiras que compõem os acontecimentos diários da vida e os significados que as pessoas vão construindo, nos seus hábitos" (CHIZZOTTI, 1992, p. 87), seja em suas casas, na rua, espaços religiosos ou em sala de aula, são todos esses comportamentos, tradições e identidades impregnados de significados, que são expressões do cotidiano.

Dito isso, entendemos o cotidiano como sendo a realidade que é vivenciada dia a dia e que faz parte da vida como repetição e invenção; “é aquilo que nos é dado cada dia (ou que nos cabe em partilha), nos pressiona dia após dia, nos oprime, pois existe uma opressão no

\footnotetext{
${ }^{1}$ Referimos aos fenômenos naturais por se tratar de uma pesquisa no ensino de Física. Sendo o objeto de estudo dessa Ciência a natureza, logo os fenômenos naturais são eventos que ocorrem na natureza por razões naturais. Como por exemplo: tempestades, furacões, formação do arco-íris entre outros.
} 
presente" (CERTEAU, 2009, p. 31), portanto, nos referimos ao cotidiano como o hoje, o agora, relacionado ao tempo presente.

Em seus livros² é possível identificar com precisão as possibilidades que Certeau dá a crer na liberdade das práticas, de enxergar e perceber diferenças nas pequenas resistências que dão fundamentos a pequenas liberdades e deslocam fronteiras de dominação, isto é, a inversão de perspectiva que fundamenta a sua Invenção do Cotidiano. No pensamento da racionalidade técnica, a forma mais eficiente para se organizar pessoas era conceder um espaço, um papel e produtos a consumir. Contrário a esse pensamento, Certeau nos mostra que "o homem ordinário" constrói o cotidiano com mil maneiras de "caça não autorizada", escapando discretamente a essa confirmação (CERTEAU, 2009). Em sua obra nos fala sobre a capacidade que o homem ordinário tem em sua prática cotidiana, utilizando as estratégias e táticas para reinventá-la. A estratégia é “cálculo (ou a manipulação) das relações de forças que se torna possível a partir do momento em que um sujeito de querer e poder [...] pode ser isolado" (p. 93). Já a tática é a "ação calculada que é determinada pela ausência de um próprio" (p. 94), ou seja,

É o movimento "dentro do campo de visão do inimigo"[...], e no espaço por ele controlado. [...] Ela opera golpe por golpe, lance por lance. Aproveita as "ocasiões" e delas depende, sem base para estocar benefícios, aumentar a propriedade e prever saídas. O que ela ganha não se conserva. Este não-lugar lhe permite sem dúvida mobilidade, mas numa docilidade aos azares do tempo, para captar no vôo as possibilidades oferecidas por um instante. Tem que utilizar, vigilante, as falhas que as conjunturas particulares vão abrindo na vigilância do poder proprietário. Ai vai caçar. Cria ali surpresas. Consegue estar onde ninguém espera. É astúcia. (CERTEAU, 2009, p. 9495).

De modo geral, as estratégias seriam as ações que acontecem em lugares de poder, que podem impor objetos, modelos de pensamento, padrões de comportamento, é o que já é prédeterminado, planejado. Já as táticas é o que surge nas circunstâncias, são as inventividades do mais fraco, a maneira como cada indivíduo se apropria dos objetos sem necessariamente fazer uso deles da forma como eles foram pensados para serem usados, ou seja, são as linhas de fuga dos sujeitos para poder dar conta de determinadas situações no cotidiano. Se deslocarmos para a sala de aula, o plano de aula do professor é a estratégia, pois houve um planejamento para sua realização, as táticas se fazem presentes através do improviso, do que não estava planejado.

\footnotetext{
${ }^{2}$ Aludimos aos livros editados no Brasil pela Editora Vozes (Petrópolis): A invenção do cotidiano: 1. Artes de fazer; A invenção do cotidiano 2. Morar e cozinhar (2009), apresentado por Luce Giard.
} 
A originalidade da obra de Certeau se encontra na forma como ele modifica a análise das práticas culturais contemporâneas. São intrinsicamente nossas vontades, ideias, sentimentos, experiências e, idealizações que se configuram o nosso cotidiano.

Certeau, então, concebe o cotidiano como lugar de beleza; das táticas de enfrentamento; lugar de invenção. $\mathrm{O}$ espaço da criatividade é o cotidiano. O sujeito (re)inventa o cotidiano através das artes de fazer o tempo inteiro. São através dessas que se dá a invenção do cotidiano, através das táticas sutis, práticas comuns, que vão modificando as normas e os códigos, e apropriando do espaço e do uso ao jeito de cada indivíduo. "O cotidiano é aquilo que nos prende intimamente, a partir do interior" (CERTEAU, 2009, p. 31).

Falar sobre práticas comuns de invenções, explorando as ações cotidianas dos sujeitos, relacionando a atividade docente no espaço escolar e de outros lugares, automaticamente nos leva a pensar e pesquisar o cotidiano referenciando os estudos de Michel de Certeau, cuja ideia é a de apreender as ações cotidianas imprevistas, porém, explícitas no dia a dia dos sujeitos que são impostas e usadas para criarem diariamente seu próprio cotidiano.

Ao contrário do que estamos acostumados no espaço escolar, que envolve a ausência de algo novo, que fuja da mesmice, do habitual, devemos considerar o cotidiano como um cenário de complexas interações humanas, no qual faz parte do inesperado, além de ser o espaço-tempo que proporciona novas aprendizagens e forja o professor em sua prática (CORRÊA, 2013).

Assim, ao invés de classificações e sistemas que limitam a vida cotidiana, é importante refletirmos o cotidiano, também, como redes de saberesfazeres ${ }^{3}$, desenvolvidas pelo sujeito cotidiano, mas que não deve ser apenas considerada como algo ou característica que acontece no cotidiano. Nesse viés, "consideramos cotidiano o próprio movimento de tessitura e partilha dessas redes. As redes não estão no cotidiano. Elas são o cotidiano! ” (FERRAÇO, 2007, p. 78).

A esse respeito,

[...] assumir os sujeitos cotidianos não só como sujeitos da pesquisa, mas, também, como nossos autores-autoras, reconhecidos em seus discursos [...] ou seja, os textos e discursos elaborados e compartilhados por esses sujeitos cotidianos da pesquisa precisam ser pensados não como citações e/ou exemplos dos discursos das autoras-autores que estudamos nas academias, mas como discursos tão necessários, legítimos e importantes quanto estes. (FERRAÇO, 2007, p. 78).

\footnotetext{
${ }^{3}$ Utilizamos em nossos textos a junção de termos feita por Ferraço inspirado na escrita de Nilda Alves.
} 
Posto isso, observar e pesquisar o cotidiano de professores e alunos pode trazer revelações surpreendentes, e potencializar os movimentos e os sujeitos considerando a legitimidade dos saberes e valores que permeiam dentro e fora da cultura escolar, suas práticas e estratégias. Embora encontremos as redes cotidianas escolares e os sujeitos, não vamos nos ater ao cotidiano escolar, somente, como o único espaço fértil dos saberesfazeres. Sobre isso, Ferraço nos afirma que,

As redes de saberesfazeres não se limitam ao território das escolas, também os sujeitos que as tecem não se reduzem aos sujeitos que lá estão por ocasião da realização das pesquisas. [...] as redes tecidas em meio á articulação dos contextos culturais, políticos, sociais, econômicos, familiares, vividos pelos sujeitos cotidianos, produzem diferentes saberesfazeres dependendo de necessidades e/ou interesses pessoais e/ou locais, das histórias de vida, formações, valores e intenções (2007, apud CORRÊA, 2013, p. 131).

Ferraço (2003) nos ajuda nessa discussão, quando afirma que é necessário para as pesquisas que se propõem a estudar e investigar os cotidianos, nos colocar como parte dele, pensando e dialogando com ele.

Nesse pensamento, Alves (2001) remete alguns movimentos como pré-requisitos para se começar a entender o cotidiano em sua complexidade e, entre eles, aparece o sentimento de mundo. De acordo com a autora, não podemos mensurar esses movimentos a um dado "lugar", mas, também, a partir do que pode ser sentido através do olhar e toque, discutido, nos milhões de eventos que cercam o pesquisador. Assim, "é preciso superar o 'paradigma do olhar', tão caro aos discursos hegemônicos da ciência moderna, como potência para nos envolvermos com os movimentosacontecimentos diários vividos pelos sujeitos que habitam as escolas" (BARCELOS, 2011, p. 114). Como nos aluda Ferraço:

[...] eu penso o cotidiano enquanto me penso; eu faço parte desse cotidiano que eu penso; eu também sou esse cotidiano; eu não penso 'sobre' o cotidiano, eu penso 'com' o cotidiano; esses momentos, movimentos, processos, tentativas, possibilidades, de pensar 'com' os cotidianos, de me pensar, possibilitam que eu me conheça ao mesmo tempo que busco conhecer os outros..., mas eu também sou esses outros [...] (FERRAÇO, 2003, p. 160).

Para Barcelos, é preciso enxergar o cotidiano escolar não como um espaço em que se pode ver algo de diferente, que nos remeta a uma observação/pesquisa e sim, buscar nos movimentos reais, do dia-a-dia, possibilidades de pensar o que acontece e como acontece (p. 113). São essas possibilidades e movimentos em que estremos imersos, atento aos 
acontecimentos, como meio de problematizar práticas que acontecem na escola, o estudo das "artes de fazer" dos alunos estudantes e professores.

As invenções cotidianas dos espaços escolares representam as múltiplas formas dos professores se alinharem às políticas que lhe são impostas e as múltiplas formas de "caça não autorizada" que refazem o cotidiano de suas práticas (CORRÊA, 2013).

A caça não autorizada, artes de fazer, astúcias sutis, são ações oriundas do trabalho docente. Em consenso com o exposto, Tardif nos remete que aos saberes oriundos da experiência, para o professor é "a condição para a aquisição e produção de seus próprios saberes profissionais. Ensinar é mobilizar uma ampla variedade de saberes, reutilizando-os no trabalho para adaptá-los e transformá-los pelo e para o trabalho” (TARDIF, 2002, p. 21).

Assim, destaca-se a importância dessas ações no trabalho docente. São através dessas, que se efetiva as experiências cotidianas que agregam ao professor seus conhecimentos, que por sua vez, devem ser projetados em sua prática. O professor em seu exercício não pode desvincular-se desse cotidiano.

Logo, entendemos que as práticas cotidianas se fazem, também, a partir das práticas pedagógicas. Conforme Bock, Furtado e Texeira (2008), a construção do conhecimento no cotidiano utiliza de vários recursos e, ao mesmo tempo, é um conhecimento improvisado, que depende da ação imediata. Nesse contexto, reconhecemos que, “[...] o exercício da docência nunca é estático e permanente; é sempre processo, é mudança, é movimento, [...] novas experiências, novo contexto, novo tempo, novo lugar, novas informações, novos sentimentos, novas interações" (CUNHA, 2004, p. 530).

Torna-se claro que as criações/invenções do/no cotidiano possibilitam a produção de saberes pedagógicos, tanto da escola, quanto dos sujeitos da pesquisa (professor e estudantes), na concretude do cotidiano e seus fenômenos naturais, a partir dos diálogos realizados em sala de aula. Assim, é importante mencionarmos o cotidiano, como parte de uma estratégia para o aprendizado, especificamente, na disciplina de Física, que exerce leis e conceitos da Ciência Natural, cujo objeto de estudo é a natureza.

Dessa forma, pensamos que a ideia de estudar e utilizar os acontecimentos cotidianos nos remete a uma ideia importante trazida por Ferraço (2007), Certeau (2008, 2009), e outros, sobre a dimensão do lugar-espaço, do vivido, do praticado, para as pesquisas com o cotidiano. 


\section{Incursões sobre memória e gestos didáticos com o cotidiano}

No intuito de enquadrar a memória como uma das revelações do cotidiano, expomos a seguinte argumentação com os gestos didáticos fundadores, conforme Nascimento (2011). São os gestos didáticos que promovem e realçam aspectos do que ensinar, atualizando as aprendizagens na sala de aula. Os gestos facultam ao professor delimitar temas a serem explorados, a explicitar analogias dos conteúdos com outros campos do conhecimento científico, a modalizar o enfoque e quantidade do que é apresentado aos alunos, a partir do reconhecimento das necessidades de aprendizagem e das circunstâncias cotidianas que cercam a atividade de ensino.

[...] os gestos didáticos fundadores presentificam e topicalizam um conteúdo em sala de aula, fazendo emergir um sistema de gestos didáticos no interior do sistema didático, tais como: 1) a forma como o professor inicia a topicalização de um objeto novo; 2) a maneira como formula e regula as tarefas em sala de aula; 3) a mediação por instrumentos para regular as atividades em sala; 4) a maneira como institucionaliza o conteúdo. (NASCIMENTO, 2011, p. 434).

Assim, quanto aos gestos didáticos fundadores, Aeby-Daghé e Dolz (2008, p. 85-86), com base em suas pesquisas no contexto suíço, propõem, conforme referenciado por Nascimento (2011):

1) a presentificação: tem por finalidade apresentar aos alunos um objeto social de referência, no suporte adequado, que passará por um processo de didatização;

2) o apontamento/ elementarização: (para este gesto, usamos o termo "delimitação" adotado por Nascimento, 2011) focaliza uma (ou mais) dimensão ensinável do objeto de ensino-aprendizagem - desconstrução e colocação em evidência dessa dimensão;

3) a formulação de tarefas: cuja porta de entrada são os dispositivos didáticos; seu estudo envolve a utilização de comandos;

4) a criação de dispositivos didáticos: os meios para enquadrar uma atividade escolar - pressupõe a mobilização de suportes (textos, esquemas, objetos reais, etc.);

5) a utilização da memória das aprendizagens: implica colocar na temporalidade o objeto de ensino e convocar as memórias das aprendizagens, para permitir utilizá-las mais tarde.

6) a regulação inclui dois fenômenos: regulações internas e as regulações locais.

7) a institucionalização: "constituída pelos gestos direcionados para a fixação do saber (externo) que deve ser utilizado pelos aprendizes nas circunstâncias novas (internas) em que serão exigidos" (NASCIMENTO, 2011, p.427). 
Dentre este gestos, destacamos o de utilização das memórias da aprendizagem nas aulas de Física, porque o gestos docente para mobilizar a memória das aprendizagens se apresenta como um gesto fundador na exposição dos conceitos pelos professores, uma vez que, por meio dele foi possível afirmar que os professores buscam relacionar situações do cotidiano para ativar e fixar conteúdos já trabalhados (institucionalização), efetuar a regulação do aprendizado, quando sintetiza conceitos da disciplina Física, e retoma com a presentificação dos conteúdos para que os alunos se apropriem e articulem o aprendido com o ensinado Esse é um gesto que, com certeza, deveria ser foco de reflexão nos cursos de formação docente.

Guardamos nossos conhecimentos e histórias de vida- vivências, experiências e lembranças- em um lugar designado - a memória - que, habitualmente é referenciada como passado. Isso nos leva a um questionamento: Sua importância, então, estaria resumida apenas a arquivar parte de nossas vidas? Este questionamento resume o conceito de memória conhecido por muitos, em outras palavras, memória seria então, como uma "caixa-preta", Mas, ela é sim um "espaço" de arquivamento como a maioria se refere, porém, a consideraremos como cotidiano.

É licito dizer, que não nos interessa os pormenores da memória, o que nos interessa é a memória como lugar onde se revozeiam acontecimentos, ou seja, onde o cotidiano vivido do sujeito é ativado. Interessa-nos é que ela tem a chave de um passado de experiências ativas, queremos provocar essa memória com o cotidiano, para que seja tratada como estratégia de ensino.

No intuito de refirmar a concepção aqui eleita apresentamos resenha da pesquisa intitulada Professores da zona rural em início de carreira: narrativas de si e desenvolvimento profissional, de Ferreira (2014), que objetivou analisar como a narrativa auto(biográfica) se configura prática de auto(formação) de professores rurais, nos anos iniciais da carreira docente. Dentre os métodos utilizados pela autora, nos contentaremos com as histórias de vida dos participantes através das escritas do diário. Ao analisarmos os resultados de sua pesquisa, percebe-se que, além das memórias se mostrarem reveladoras dos sujeitos e as narrativas auto(biográficas) escritas, potencializadoras do desenvolvimento profissional, foi que no diário dos professores estavam as memórias deles, mas ao mesmo tempo que eles traziam as memórias, traziam o cotidiano. Porém, nos diários a presença do cotidiano era ainda maior que a memória, porque a memória se faz no cotidiano.

\footnotetext{
${ }^{4}$ Caixa-preta ou caixa-negra é o nome popular de um sistema de registro de voz e dados existentes nos aviões
} 
Os momentos descritos nos diários revelam o cotidiano dos dois colaboradores desta pesquisa e alguns aspectos de suas vidas pessoais e profissionais. A escrita de Cientista é marcada pelo fato de ser descritiva e de se basear na rotina: é uma escrita do dia-a-dia [...] a repetição está presente nas escritas dos diários, mas neles encontra-se também o novo, isso abre possibilidades de formação, pois demarcam lugares já citados, mas não explorados; marcam a rotina e o dito pela primeira vez e como essas coisas se relacionam aos modos de viver desses sujeitos [...] (FERREIRA, 2014, p. 148).

É notório o cotidiano nos diários, porque esses foram feitos de memória, embora a autora trate do cotidiano. Então, mesmo trabalhando com história de vida dos professores de zona rural numa abordagem auto(biográfica), Ferreira não enfatiza que foram a partir das memórias, porque a própria abordagem já dá conta das memórias auto(biográficas), mas que a autora chama atenção para as escritas dos professores. Logo, essa pesquisa ao mesmo tempo que era diário, onde os professores faziam todo dia a mesma coisa e escreviam, faziam também a mesma coisa de maneira diferente. A capacidade do homem ordinário de reinventar está exatamente na repetição e na invenção de fazer todos os dias as mesmas coisas de maneira diferente, e era ali que estava as possibilidades de formação dos sujeitos, e a abordagem auto(biográfica) se consolidava na pesquisa como investigação formação a partir do cotidiano com essa possibilidade. Nessa perspectiva da autora, a memória também foi trabalhada, porém, imersa na perspectiva cotidiana e não a memória na perspectiva história, pois, nenhum diário é escrito sem memória.

Dessa forma, a memória é construída a partir das histórias de vidaexperiências/vivências- pessoais e coletivas que se convergem em conhecimentos expressos na sociedade. Logo, podemos perceber que o ser social, está vinculado ao cotidiano vivido, por meio de relações efetivadas na sociabilidade. Assim, a memória não se constrói do nada, ela se dá a partir das relações (passado-presente) que os sujeitos estabelecem entre si. Adotemos então, inicialmente a noção de memória como cotidiano vivido.

Abdicaremos da abordagem geral sobre memória para, a partir deste momento realçar cotidiano e memória didática, no tópico a seguir. Há uma conexão interessante no que se refere ao cotidiano e a memória didática. Quero dizer, existe uma interdependência ao considerarmos o cotidiano (presente) espaço de criação, rotina e repetição, mas que se dá no meio social a partir de interações com o outro e consigo mesmo, que nos direciona a experiências e conhecimentos guardadas na memória (passado) que são remetidas ao presente com novos sentidos e significados. 
Assim, é claro a relação entre esses espaços, e estabelecemos a memória como cotidiano vivido, articulado ao social. Consoante a isso, o autor Pais nos remete ao o cotidiano como "uma rota de conhecimento. Quer isto dizer que o cotidiano não é uma parcela isolável do social" (PAIS, 2001, p. 31). Uma vez que, nossas experiências, tensões, conflitos, mudanças e crises, são ordinariamente objetos da sociologia. Assim, para o autor "a fonte primeira de todo o conhecimento é o cotidiano, é o vivido" (PAIS, 2001, p. 47).

A memória se reafirma como cotidiano porque abarca essa dimensão temporal (presente e passado) e se torna presente quando lhe é dado um novo sentido e um novo significado.

\section{A relação da memória didática e do cotidiano como estratégia de ensino}

O cotidiano, embora, esteja bastante presente no nosso dia a dia, ainda é pouco discutido em sala de aula, principalmente, para fazer relações com o conteúdo de Física. De acordo com Ferreira (2017), utilizar desse meio como forma de iniciar ou explicitar conceitos, tende a tornar os conteúdos mais compreensíveis, facilitando o processo de ensino-aprendizagem dos estudantes e, fugindo da visão simplista da Física como uma cultura inútil, em que suas questões não passam de obrigações escolares, sem vínculo com a vida real, pois, de acordo com Walker, "a Física e seus problemas existem no mundo real e cotidiano onde vivemos, trabalhamos, amamos e morremos". (WALKER, 2001, p. 21).

$\mathrm{Na}$ escola, este é perceptível em seus acontecimentos e repetições, ao mesmo tempo que a escola repete sua rotina (horário de entrada/saída, intervalos etc), ela também inventa, cria, muda, transforma. Do seu jeito, a escola também se apropria do cotidiano, igualmente ao ensino.

O ensino pode ser projetado de várias formas. Vemos isso ao observarmos que cada professor ensina de uma maneira diferente, uma vez que, cada disciplina requer um ensino diferente, conforme as artes de fazer do sujeito e da própria disciplina que pede uma especificidade. São nessas formas variadas, nas astúcias criadas pelo sujeito professor, nas invenções diárias em sala de aula que enxergamos o cotidiano no ensino.

No que se refere a aulas ${ }^{5}$ transcritas, ficou claro a admiração e respeito que os estudantes têm pela professora, e a forma como esta aproveita da situação para chamar atenção dos estudantes para o conteúdo programado, isso facilita de certa forma a entrada para qualquer estratégia metodológica de ensino, nesse caso, o cotidiano.

${ }^{5}$ Essas aulas são das três turmas $\left(1^{\circ}, 2^{\circ}\right.$ e $3^{\circ}$ ano) do Ensino Médio, sendo para essas, a mesma professora. 
Durante as observações foi possível perceber diversos acontecimentos, tanto dos alunos como da professora. A interação entre aluno-aluno, professor-aluno é rica no cotidiano escolar. Cheio de significados e identidades que tecem as redes cotidianas das quais é preciso estar imerso para compreender e utilizá-las para aprendizagem. A professora em algumas aulas usou o cotidiano para facilitar a explicação, e consequentemente, a aprendizagem do aluno, durante a explanação do conteúdo Grandezas e Unidade de medida.

Nos exemplos utilizados pela professora, é citado o uso de falas comuns dos alunos a irem ao supermercado ou qualquer outro lugar que se deseja comprar alguma coisa, mas por se tratar de uma turma relativamente jovem, a professora optou por dar um exemplo que geralmente é pedido pelos pais: "filho compra 21 de leite na padaria", "filha compra $3 \mathrm{~kg}$ de carne no açougue", "filho compra 5m de barbante no armarinho". O uso desse exemplo possibilitou ainda mais a interação entre a professora e os alunos, bem como o entendimento do conteúdo, pois através do mesmo, da importância da unidade de medida para determinadas elementos os alunos conseguiram enxergar a física em suas próprias práticas comuns.

Quando se trata do cotidiano no ensino de Física pensamos que nem tudo o que é aprendido realmente tem alguma utilidade prática em nossas vidas. Entretanto, muito do que é estudado como idealização de modelos, na verdade possui aplicações no nosso dia a dia, desde as atividades físicas que realizamos (correr, andar, jogar qualquer esporte, cozinhar, escovar os dentes etc) até os equipamentos sofisticados que usamos, como os smartphones, notebooks relógios, televisão, internet entre outros, são feitos que precisam da Física para serem criados ou explicados, bem como os fenômenos naturais (arco-íris, propagação de ondas, conservação de energia, erosão etc). Por isso, a Física é uma das que mais dispõe meios para ensinar, porque ela está intimamente ligada a vida real do sujeito, em outras palavras, a natureza e vários acontecimentos cotidianos da vida de qualquer ser humano, é interpretado pela Física, com isso, destaca-se a importância de explorar o cotidiano no ensino.

A memória desprovida da carga semântica de memória didática, por sua vez, não é isoladamente estratégia, para ela ser estratégia, ela tem que ser reatualizada pelos mecanismos da docência, porque não pode passar de estratégia sem ser cotidiano onde ela foi construída e onde ela deixou de ser passado para ser presente, por isso abarca presente/passado que são dimensões temporais de uma estratégia de ensino. E pela rede de conhecimento, saberesfazeres, movimentos e acontecimentos que ela é uma possibilidade de estratégia de ensino. 
Dito isso, não podemos nos distanciar da noção de que o cotidiano vivido se refere a memória. Como menciona Ferraço (2015), defendido por Certeau (2008, 2009), Augé (1997), Lefebvre (1991), os estudos com os cotidianos possibilitam deslocamentos temporais, a respeito do cotidiano vivido, isto é, da memória. Sendo assim,

A memória é ativada visando, de alguma forma, ao controle do passado (e, portanto, do presente). Reformar o passado em função da presente via gestão das memórias significa, antes de mais nada, controlar a materialidade em que a memória se expressa (das relíquias aos monumentos, aos arquivos, símbolos, rituais, datas e comemorações). (SEIXAS, 2001 apud AUGUSTIN; AUGUSTIN, 2012, p. 120).

Então, se a memória é um instrumento social alicerçado a um cotidiano vivido, é possível trazer à tona lembranças, conhecimentos e acontecimentos de um cotidiano passado para o cotidiano presente, permitindo assim, a ressignificação da memória. Sobre isso, Cunha ressalta que "quando uma pessoa relata os fatos vividos por ela mesma, percebe-se que reconstrói a trajetória percorrida dando-lhe novos significados" (CUNHA, 1997, p. 187). A ressignificação da memória faz emergir elementos como os fatos vividos, que ao se relacionar com o cotidiano presente potencializa a aprendizagem.

Assim, ao retomar aprendizagens e experiências ${ }^{6}$ por meio da memória, cotidiano presente no qual se desenvolve a aula abre uma possibilidade de construção de sentidos diante dos novos conhecimentos (MOREIRA, 1999). A memória é um trabalho feito a partir das dimensões temporais. Essas memórias situam-se num tempo passado e num tempo presente e essas são/estão no tempo e espaço. As memórias possibilitam a retomada das aprendizagens e experiências.

Assim, chegamos a memória das aprendizagens como um gesto fundador no contexto de nosso estudo. A memória das aprendizagens (ou memória didática) é um gesto didático fundador importante no ensino. A ativação da memória faz parte do desenvolvimento das aulas observadas. O professor, consciente ou inconscientemente, dirige-se aos alunos com gestos do tipo:

Continuando com a explicação do conteúdo Grandezas, a professora utilizou bons exemplos na lousa. Em um determinando momento na parte de

\footnotetext{
${ }^{6}$ Jorge Larrosa Bondía (2002), fala que "a experiência é o que nos passa, o que nos acontece, o que nos toca. Não o que se passa, não o que acontece, ou o que toca. A cada dia se passam muitas coisas, porém, ao mesmo tempo, quase nada nos acontece" (p. 21). Tratamos as experiências nesse pensamento, no da subjetividade, por isso as memórias vêm para o cotidiano como experiências, porque aquilo que não foi experiência, os alunos não irão lembrar. A memória, já vem carregada de experiências.
} 
transformações de unidades de medida (que faz parte do conteúdo), uma aluna disse não ter entendido a explicação, a professora então, voltou a parte em que a aluna não havia entendido, explicou de duas maneiras diferentes, quando perguntado a aluna se ainda havia dúvidas ou se mais alguém tinha dúvidas, todos disseram que não. A aula então foi finalizada as 11:30 após sanar as dúvidas, concluindo o conteúdo programado. (Aula 1e 2)

A memória das aprendizagens pode ser mobilizada em qualquer procedimento didático do trabalho docente. Ela é transmitida de grupo de geração a novas gerações de docentes, como um DNA cultural, em que um coletivo de educadores constroem um imaginário (docente) que influencia nas formas e modos de organizar e desenvolver as aulas. Há várias maneiras de mobilizar a memória das aprendizagens no ensino. Da mesma forma, várias são as ferramentas que proporcionam a articulação deste gesto didático.

Assim, é distribuído aos alunos materiais de baixo custo como: copo e
canudo plástico, pedaços de papel higiênico, papel espelhado e linha de
costura branca. Explicou passo a passo como os alunos devem montar o
experimento. Percebe-se o envolvimento de toda a turma na prática
experimental. O experimento dá certo e a alegria dos alunos e professora é
visível. Faltando 30 minutos para encerrar a aula, a professora pede as
duplas que entreguem um texto falando sobre o que foi observado no
experimento, qual fenômeno estudado e quais processos de eletrização
ocorreram. No fim da aula, após a entrega dos textos, a professora entrega a
lista de exercício e marca a data do sorteio e defesa da mesma para próxima
aula. (Aula 17 e 18)

As experiências quando vem à tona como memórias, serão ressignificadas, permitindo que o sujeito vivencie outras experiências pela própria experiência como memória. Isso ficou claro ao trabalhar o exemplo ${ }^{7}$ da elasticidade em sala de aula, pois ficou guardado na memória do aluno como lembrança uma brincadeira que serviu para facilitar sua aprendizagem.

A memória guarda o cotidiano passado, mas que ao emergir, torna-se cotidiano presente, portanto pode ser acessado para o ensino de Física, já que as memórias trazem à tona experiências, anteriormente vivenciadas, que pode/devem ser relacionadas a aprendizagem atual. É valido salientar, que nem toda vivência é experiência, mas toda experiência é vivência.

\footnotetext{
${ }^{7}$ Este exemplo, se deu através da experiência de estágio durante a graduação do primeiro autor deste texto, para facilitar o entendimento do conceito de energia elástica, foi usado como exemplo o "ono um" e o "estilingue/bardock" -brincadeira e brinquedo- que possuem elasticidade. Após a explicação, um aluno me disse que nunca pensou que o fato dele ter brincado com o estilingue, poderia fazer hoje facilitar aprender física. Quer dizer, na memória do aluno, brincar de estilingue é uma lembrança boa da infância, mas que foi trazida para o presente como cotidiano, aquela experiência, para ele vivenciar uma outra experiência, que é a de aprender física, o assunto elasticidade.
} 
Fazer com que os alunos tragam à tona lembranças (passado), é deslocar essa mesma, para um cotidiano (presente). Portanto, a memória aqui tratada começa a pertencer a um cotidiano presente, através da sua ressignificação. O aluno ao acessar a memória e ressignificá-la, agrega novos significados, tornando-a cotidiano presente.

Enfatizar o ensino de Física com a utilização de fórmulas, em situações artificiais, desvinculando a linguagem matemática e não percebendo a importância que essas fórmulas trazem para o aprimoramento do conhecimento; insiste na solução de exercícios repetitivos, pretendendo que a aprendizagem ocorra pela automatização ou memorização e não pela construção do conhecimento através das competências adquiridas pelos professores (BRASIL, 2006). Para Carvalho Júnior:

O ensino de física em particular, deve permitir que os alunos, através de atividades propostas durante as aulas, tenham acesso a conceitos, leis, modelos e teorias que expliquem satisfatoriamente o mundo em que vivem, permitindo-lhes entender questões fundamentais como a disponibilidade de recursos naturais e o risco de se utilizar uma determinada tecnologia [...] (CARVALHO JÚNIOR, 2011, p. 16).

Esse ensino, nos dias atuais, pode ser alterado, se as realidades dos alunos estiverem mais presentes na sala de aula. Os professores são peça-chave para que isso aconteça. $\mathrm{O}$ ensino de Física é carente de melhoria tanto nos recursos quanto na metodologia, por isso os professores precisam possibilitar aulas e atividades variadas para que o aluno tenha mais de uma possibilidade para aprender. As aulas práticas e experimentais e estratégias aproximadas da realidade do aluno são boas alternativas no processo ensino-aprendizagem.

O ensino de Física é tempo cheio de vida, realidade e cotidianidade, porém, o grande problema é a forma como se ensina, são as artes de fazer. A maneira como ele vem sendo feito: mecânico, baseado apenas na lousa e piloto, piloto e lousa, quando na verdade a Física é memória e perspectivas sociais. Comparada a outras áreas de conhecimento, é a que está muito mais próxima da vida das pessoas.

Os fenômenos estão presentes em diversos momentos do nosso dia. Por exemplo: ao fazer comida, abrir uma torneira, ligar a luz, entre outros, são coisas que fazemos, mas não relacionamos a Física. Ao cozinhar é necessária uma transformação de um estado para outro do gás, abrir uma torneira exige usar uma força aplicada juntamente com movimento rotacional, o circuito elétrico, diferença de potencial e campo elétrico, são feitos oriundos e fundamentais para ligar a luz elétrica. Então, as coisas mais simples, cotidianas e mais repetidas da vida, tem a presença da Física. Tudo isso é repetição (e cotidiano). As relações 
entre os conhecimentos científicos e os adquiridos no cotidiano são particularmente de grande importância para o processo ensino-aprendizagem, a partir dos gestos didáticos do professor com a utilização da memória e do cotidiano como estratégias de ensino.

\section{Considerações finais}

As possibilidades que a ativação da memória e os acontecimentos do cotidiano possibilitam tendem a colocar em evidência que o trabalho docente se compõe de acontecimentos discursivos inerente aos processos de interação verbal da aula e que os enunciados revozeados pelo docente e estudantes, antes de engessar os conteúdos, facultam aprendizagens significativas do tópico da aula.

Os resultados apresentados neste artigo, mesmo que iniciais, afirmam a produtividade dos conceitos de memória didática e de cotidiano para propositar metodologias e estratégias de ensino que consideram as experiências dos estudantes e o conjunto de significações que podem emergir das interações na sala de aula com o tópico a ser ensinado.

Corroboramos, assim, que possibilitar aos professores reflexões sobre os conceitos de memória, cotidiano e gestos didáticos como objeto de ensino nos cursos de formação inicial e continuada, os cursos de licenciatura, qualifica a formação docente.

Assumimos, ainda, memória da aprendizagem no mesmo sentido de memória didática, pois esta se circunscreve nos contextos de ensino da aula. Embora não seja novidade que o estudo de Física é pouco valorizado, ressaltam-se a importância e a necessidade dos professores refletirem sobre a real leitura que os alunos fazem da disciplina Física, enfatizando sua relação com o cotidiano e a memória

Dessa forma, o profissional em sala de aula deve assumir um papel que ultrapasse sua responsabilidade na transição de conhecimento, é preciso também, usar estratégias que permitam os alunos a refletir o mundo a sua volta, buscando relações do que estuda ao seu cotidiano.

Portanto, o ensino de Física, em particular, deve permitir que, por meio de metodologias e estratégias utilizadas pelo professor durante suas aulas, os estudantes tenham acesso a conceitos, leis e teorias que expliquem satisfatoriamente o mundo em que vivem. E dessa forma, destaca-se o uso da memória e cotidiano dos alunos como estratégia para ensinar, relacionando as suas "artes/modos de fazer" aos fenômenos físicos que preenchem o cotidiano e as práticas cotidianas já vividas. 
Foi sobre o enfoque da memória didática que este trabalho se debruçou, recortando situações de aulas observadas no enquadre de gestos didáticos fundadores. Esperamos ter atendido o nosso intuito que foi o de expor a necessidade de mobilizar a memória e o cotidiano para desenvolver aulas criativas e propositar conhecimentos significativos para a aprendizagem de conteúdos da área de Física.

\section{REFERÊNCIAS}

AEBY-DAGHÉ, Sandrine.; DOLZ, Joaquim. Des gestes didactiques fondateurs aux gestes spécifiques à l'enseignement-apprentissage du texte d'opinion. In: BUCHETON, Dominique; DEZUTTER, Olivier (Org.). Le développement des gestes professionnels dans

l'enseignement du français: un défi pour la recherche et la formation. Bruxelas: De Boeck, 2008. p. 83-105.

ALVES, Nilda. Decifrando o pergaminho: o cotidiano das escolas nas lógicas das redes cotidianas. In: Oliveira, Inês Barbosa de; ALVES, Nilda (Org.). Pesquisa no/do cotidiano das escolas: sobre redes de saberes. Rio de Janeiro: DP\&A, 2001. p. 13-38.

AUGÉ, Marc. Por uma antropologia dos mundos contemporâneos. Rio de Janeiro: Bertrand Brasil, 1997.

AUGUSTIN, Roberta Lopes; AUGUSTIN, Sérgio. Memória e suas implicações na vida cotidiana: análise teórica. Revista Métis: história \& cultura, v. 11, n. 21, p. 115-130, jan/jun. 2012.

BARCELLOS, Adriana Pionttkovsky. Currículos em redes tecidos com os cotidianos da EEEFM David Roldi: sobre os movimentos/processos de implementação e os primeiros usos do documento "currículo básico da escola estadual". Dissertação (Mestrado). Mestrado em Educação. Universidade Federal do Espirito Santo: Vitória-ES, 2011.

BOCK, Ana Mercês Bahia; FURTADO, Odair; TEXEIRA, Maria de Lourdes Trassi. Psicologias: uma introdução ao estudo de Psicologia. 14. Ed. São Paulo: Saraiva, 2008.

BOSI, Ecléa. Memória e Sociedade: lembranças de de velhos. São Paulo: Companhia das Letras, 1994. 14 ed

CARVALHO JUNIOR, Gabriel Dias de. Aula de física: do planejamento à avaliação. São Paulo: Livraria da Física, 2011.

CERTEAU, Michel de. A invenção do cotidiano: 1, artes de fazer. 16 ed. Tradução de Ephraim Ferreira Alves. Petrópolis, RJ: Vozes, 2009, p. 9-166.

CERTEAU, Michel; LUCE, Giard; PIERRE, Mayol. A invenção do cotidiano: 2, morar, cozinhar. 7 ed. Tradução de Ephraim Ferreira Alves. Petrópolis, RJ: Vozes, 2008, p. 13-202. 
CHIZZOTTI, Antonio. O cotidiano e as pesquisas em educação. In: FAZENDA, Ivani (Org.). Novos enfoques da pesquisa educacional. São Paulo: Cortez, 1992.

CORRÊA, Thiago Henrique Barnabé. O cotidiano escolar como espaço-tempo de formação e reflexão. Revista Educação, Batatais, v. 3, n. 1, p. 129-137. Jun, 2013.

CUNHA, Maria Isabel. Conte-me agora! As narrativas como alternativas pedagógicas na pesquisa e no ensino. Revista da Faculdade de Educação, São Paulo, v. 23, n. 1/2, p. 185195, jan./dez. 1997.

CUNHA, Maria Isabel. Diferentes olhares sobre as práticas pedagógicas no Ensino Superior: a docência e sua formação. Educação, Porto Alegre, v. 54, n. 3, p. 525-536, set/dez. 2004.

FERRAÇO, Carlos Eduardo. Currículos, culturas e cotidianos escolares: afirmando a complexidade e a diferença nas redes de conhecimentos dos sujeitos praticantes. Leitura: Teoria \& Prática, Campinas, v.31, n.60, p.81-103, jun. 2013.

FERRAÇO, Carlos Eduardo. Pesquisa com o cotidiano. Educação \& Sociologia, Campinas, v. 28, n. 98, p. 73-95, jan./abr. 2007.

FERRAÇO, Carlos Eduardo. Eu, caçador de mim. In: GARCIA, Regina Leite (Org.).

Método: pesquisa com o cotidiano. Rio de Janeiro, 2003.

FERREIRA, Lúcia Gracia. Professores da zona rural em início de carreira: narrativas de si e desenvolvimento profissional. Tese (Doutorado). Programa de Pós-Graduação em Educação. Universidade Federal de São Carlos: São Carlos-SP, 2014.

FERREIRA, Álex de Carvalho. Percepção dos estudantes sobre o ensino de Física na Educação Básica e sua relação com ingresso no ensino superior. Monografia (Graduação). Curso de Licenciatura em Física: Universidade Estadual do Sudoeste da Bahia- ItapetingaBA, 2017.

LARROSA, Jorge. Notas sobre a experiência e o saber de experiência*. Revista brasileira de Educação. n. 19, jan/fev/mar/abr. 20-29, 2002.

MOREIRA, Marco Antônio. Aprendizagem significativa. Brasília: UNB, 1999.

NASCIMENTO, Elvira Lopes. (Org.) (2011). A dupla semiotização dos objetos de ensinoaprendizagem: dos gestos didáticos fundadores aos gestos didáticos específicos. Signum: Estudos da Linguagem, Londrina, v. 14, n.1, p. 421-445.

PAIS, José Machado. Vida Cotidiana: enigmas e revelações. São Paulo: Editora Cortez, 2001.

TARDIF, Maurice. Saberes docentes e formação profissional. Petrópolis: Vozes, 2002.

WALKER, Jearl. O grande circo da física. Coleção Aprender Fazer Ciência. 2.ed Lisboa: Gradiva, 2001. 


\section{SOBRE OS AUTORES:}

\section{Álex de Carvalho Ferreira}

Mestrando em Educação pela Universidade Estadual do Sudoeste da Bahia (UESB). Integrante do Centro de Pesquisa e Estudos Pedagógicos (CEPEP). Membro do Grupo de Pesquisa Linguagem e Educação (GPLEd); Bolsista CAPES. E-mail: aledcferreira@hotmail.com

\section{iD http://orcid.org/0000-0002-4618-164X}

\section{Ester Maria de Figueiredo Souza}

Doutora em Educação pela Universidade Federal da Bahia (UFBA). Professora Plena da Universidade Estadual do Sudoeste da Bahia (UESB), atuando no curso de Licenciatura em Letras, no Programa de Pós-graduaçao em Letras: Cultura, Educação e Linguagens, e do Programa de Pós-graduação em Educação. Líder do Grupo de Pesquisa Linguagem e Educação - GPLEd/CNPQ/UESB. E-mail: efigueiredo@uesb.edu.br

(iD http://orcid.org/0000-0001-5992-0184 